\title{
Reflets
}

Revue ontaroise d'intervention sociale et communautaire

\section{Colloque Sensibiliser, décider, agir, les 14, 15 et 16 octobre 1994}

\section{Cécile Coderre}

Volume 2, numéro 1, printemps 1996

Contrer la violence subie par les femmes et les enfants en milieu familial

URI : https://id.erudit.org/iderudit/026124ar

DOI : https://doi.org/10.7202/026124ar

Aller au sommaire du numéro

Éditeur(s)

Reflets : Revue ontaroise d'intervention sociale et communautaire

ISSN

1203-4576 (imprimé)

1712-8498 (numérique)

Découvrir la revue

Citer ce compte rendu

Coderre, C. (1996). Compte rendu de [Colloque Sensibiliser, décider, agir, les 14, 15 et 16 octobre 1994]. Reflets, 2(1), 211-212. https://doi.org/10.7202/026124ar

Tous droits réservés (C) Reflets : Revue ontaroise d'intervention sociale et communautaire, 1996
Ce document est protégé par la loi sur le droit d'auteur. L'utilisation des services d'Érudit (y compris la reproduction) est assujettie à sa politique d'utilisation que vous pouvez consulter en ligne.

https://apropos.erudit.org/fr/usagers/politique-dutilisation/ 


\section{Colloque Sensibiliser, décider, agir, les 14, 15 et 16 octobre 1994}

\section{C édile C oderre}

É cole de service sodal, U niversité d'O ttawa

Le colloque Sensibiliser, déadder, agir tenu à 0 ttawa, les 14,15 et 16 octobre 1994 est le premier colloque sur la violence sexuelle regroupant des femmes de tout I'O ntario français, dans l'intention manifeste d'éclairer l'ensemble du dossier de la violence, d'y inclure la question de la santé des femmes ains que l'action politique.

Ce colloque, comme nous le rappellent les actes, a débuté par une pièce de théâtre d'une forme particulière :le théâtre invisible. I ssue des pratiques de conscientisation, cette pièce de théâtre suscite la controverse, car sa forme privilégiée est la confrontation et I'utilisation du paradoxe. Soulignons que cette pièce a atteint ses objectifs puisque de prime abord, les femmes ont été confrontées aux divers enjeux présents dans l'intervention féministe auprès des femmes ayant subi une agression à caractère sexuel.

Un des soucis des organisatrices de ce colloque était de préparer un bilan de l'intervention auprès des femmes et de dégager des priorités d'action. C'est pourquoi nous retrouvons dans les actes du colloque des textes faisant le bilan politique et sociojudiciaire de ce dossier. À ce titre, le texte d'Andrée Côté mérite qu'on s'y arrête, à cause de la richesse de son information et la finesse de son analyse féministe. L'ensemble des textes des conférencières et des animatrices d'ateliers est groupé dans la section des actes intitulée: L es connaissances transmises. La plupart de ces textes incluent une bibliographie. Le champ complet de l'agression à caractère sexuel est couvert, depuis le dévoilement jusqu'à l'analyse des mécanismes de survie, en passant par la nécessité des groupes d'entraide.

Les actes du colloque sont intéressants à plus d'un égard : ar- 
chives, histoire de groupes sociaux, présentation de pratiques féministes d'intervention et outils d'intervention. C'est ainsi qu'une section complète est consacrée à des exercices et des outils d'intervention, entre autres l'identification de la diversité (le cercle du pouvoir), la perception que nous avons des médecins, l'impact du dévoilement, les communications contemporaines.

La quatrième partie est une ouverture à la parole des femmes. $R$ econstituésà partir des bannières exposées dans la salle principale de la plénière, cestémoignages en tant que messages au personnel politique sont intéressants et percutants. C'est ains que l'on trouve des témoignages de survivantes d'agressions sexuelles commises par des professionnels de la santé. Elles expriment leurs besoins en ces termes: formation d'enquêteuses d'expression française et appui financier lors des poursuites. D'autres témoignent de leur consommation d'alcool à la suite d'agressions sexuelles, et la méconnaissance de cette question par les médecins. Elles demandent qu'on sensibilise les professionels de la santé, qu'on leur fasse connaître les signes précurseurs et les ressources disponibles.

Enfin la cinquième partie présente les ressources disponibles en 0 ntario français, groupes d'intervention, services d'intervenantes et de consultantes. $0 \mathrm{n}$ peut voir la richesse et la diversité des expertises et compétences.

La lecture des actes de ce colloque est intéressante et essentielle pour toute intervenante désireuse de connaître l'ensemble du dossier sur les agressions à caractère sexuel en 0 ntario français. 